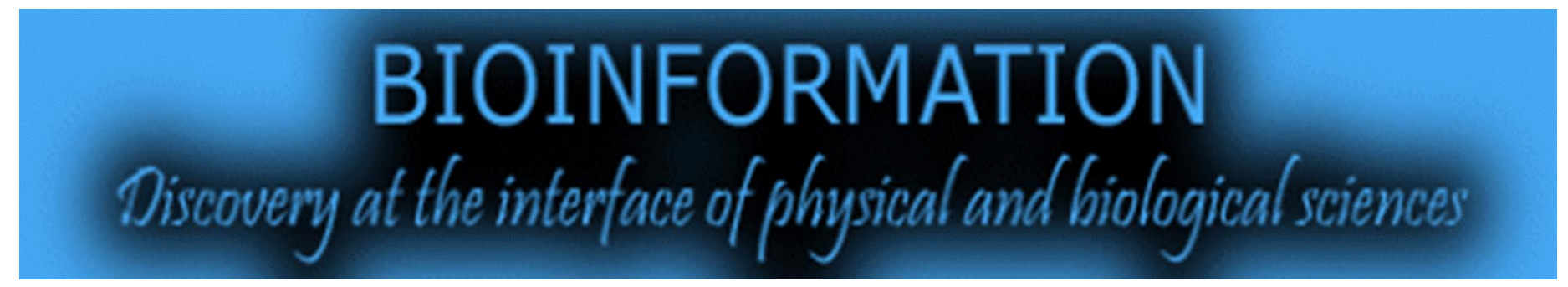

\title{
Leaf Senescence and GABA Shunt
}

\author{
Mohammad Israil Ansari*, Saba Hasan \& Syed Uzma Jalil
}

Amity Institute of Biotechnology, Amity University Uttar Pradesh, Lucknow Campus, Gomti Nagar Extension, Lucknow-226 028 India; Mohammad Israil Ansari - Email: miansari@amity.edu; ansari_mi@hotmail.com; *Corresponding author

Received December 02, 2014; Accepted December 18, 2014; Published December 31, 2014

\begin{abstract}
:
Leaf senescence is highly regulated and complex developmental process that involves degradation of macromolecules as well as its recycling. Senescence process involves loss of chlorophyll, degradation of proteins, nucleic acid, lipid and mobilization of nutrients through its transport to the growing parts, developing fruits and seeds. Nitrogen is the most important nutrient to be recycled in senescence process. GABA-transaminase ( $\gamma$-aminobutyric acid) is found to play very important role in nitrogen recycling process through GABA-shunt. Therefore, it is of interest to review the significance of GABA shunt in leaf senescence.
\end{abstract}

Keywords: Leaf Senescence, Nutrients, GABA ( $\gamma$-aminobutyric acid), GABA-shunt, GABA-transaminase.

\section{Background:}

Senescence is the last step of leaf development process and it takes place in a highly synchronized manner by degradation and recycling process leading to organ death $[\mathbf{1}, \mathbf{2}, \mathbf{3}, \mathbf{4}, \mathbf{5}, \mathbf{6}]$. During senescing process nutrients synthesized in leaves such as proteins, lipid and nucleic acid are degraded and redistributed to the growing parts and reproductive organs for developing fruits and seeds $[7,8,9,10,11]$. Senescence might reduce productivity of crop if senescence induced prematurely under unfavourable weather conditions or any other stress [11].

External factors as well as internal factors will induce the senescence. A lot of efforts have been done to know the mechanism of leaf senescence process for crop productivity [12, 13]. This is complex process containing a series of physiological, biochemical event and thousands of genes regulating senescence event in plants. In plant leaf senescence, nitrogen is the most important nutrient to be recycled and $70 \%$ of nitrogen is stored in chloroplast [6]. Presently nutrient recycling process during leaf senescence is not well known. It has been reported that GABA-transaminase ( $\gamma$-aminobutyric acid) has very important role in nitrogen recycling process in rice leaf senescence process through GABA shunt [14]. Similar information has been reported in post-harvest citrus fruit nitrogen metabolism through GABA shunt [15]. It is very important to note that GABA shunt is essential for normal plant growth [16]. GABA is a non-protein amino acid, it is known as inhibitory neurotransmitter in mammalian central nervous system [17]. Rapid GABA accumulation has been reported in plants under biotic and abiotic stress conditions [18] and evolvement of GABA-shunt in responses to abiotic stress has been reported $[16,19]$.

\section{Role of GABA Shunt in Leaf Senescence Process}

GABA is one of the special interest of molecule among stress responsive metabolites as this molecule is accumulated at various biotic and abiotic stress conditions including leaf senescence process. GABA is metabolized via a pathway composed of three enzymes called GABA shunt. GABA shunt pathway composed of enzyme cytosolic glutamate decarboxylase (GAD), mitochondrial GABA transaminase (GABA-T) and succinic semialdehyde dehydrogenase (SSADH) $[20,21]$. It has also been reported that GABA shunt is way to assimilate carbons from glutamate and to create carbon and nitrogen flues that enter into tricarcoxylic acid cycle (TCA cycle) $[22,23,24]$.

In leaf senescence process, once leaf senescence started the degradation of macromolecules ie. proteins, lipids and nucleic acid will took place and these will be transported to the 
growing parts of plants, developing fruits and seeds $[25,7,8$ 10]. Nitrogen which is a key important nutrient to be recycled and mobilized in senescing process [6]. Nitrogen which is present in these macromolecules will be converted into glutamine and asparagine in the leaf senescence and these amino acids (glutamine and asparagine) will be transported to the growing parts and growing seeds and fruits of plants through phloem [26]. As shown in Fig. 1 in senescence process protein with the help of proteases will be converted into aamino acid and from this a-amino acid with the help of transaminase will be converted into glutamate and a-keto acids and ammonia is released. This ammonia can be used to convert into glutamate into glutamine with the help of enzyme glutamine synthetase (GS) and further this glutamine with enzyme asparagine synthetase (AS) will be converted into asparagine [27]. Part of glutamate will be converted into GABA with the help of glutamate decarboxylase (GAD). Process of GABA to glutamate conversion speed up when there is inhibition of protein synthesis [28]. The metabolism of GABA is related to glutamate metabolism in senescence process and this way the glutamate will enter into GABA shunt. This GABA is converted into succinate in the mitochondria with the help of enzyme succinic semialdehyde dehydrogenase (SSADH). So GABA shunt pathway converts glutatmate into succinate via GABA [29] in the plant leaf senescence and nitrogen assimilation. In case of post-harvest citrus fruit GABA shunt not only catabolise organic acid but this link between organic acid metabolism and amino acid production as a result in this process inorganic nitrogen assimilated mainly into four amino acids ie.glutamic acid, glutamine, aspartic acid and asparagine. Glutamine and asparagine are transported for plant growth [30, 15].

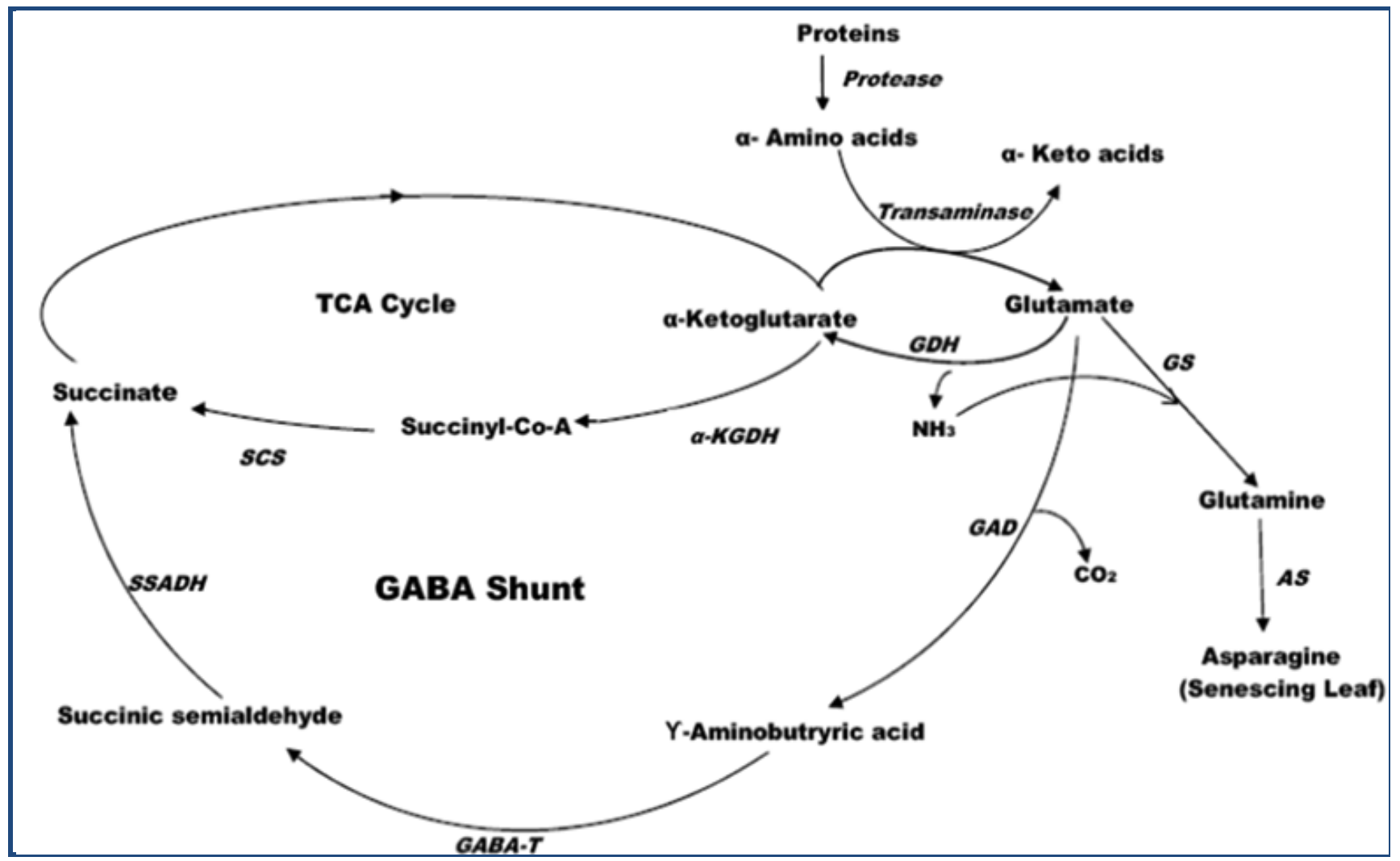

Figure 1: Role of GABA shunt in metabolism of proteins and amino acids during leaf senescence GDH: Glutamate dehydrogenase, GAD: Glutamate decarboxylase, $\alpha-K G D H: \alpha$-ketoglutarate dehydrogenase, GABA-T : GABA-transaminase, SSADH : Succinic semialdehyde dehydrogenase, SCS : Succinyl CoA synthetase, GS: Glutamine synthetase, AS: Asparagine synthetase, TCA : Tricarboxylic Acid. The arrow indicates the direction of the reaction during senescence.

So GABA shunt is involved in nitrogen metabolism and its transport in leaf senescence that finally enters into TCA cycle (Figure 1) [23, 24]. In my opinion the production of succinate through GABA shunt is very important, in case TCA cycle does not provide enough succinate as GABA shunt is important for normal plant growth [16].

\section{Conclusion:}

Leaf senescence is a complex process progressing with age, different internal and environmental adverse condition. Nitrogen is known to be the most important nutrient to be recycled in senescence process. GABA shunt plays an important role in nitrogen metabolism through TCA cycle.

GABA shunt is a key signalling and metabolic pathway in senescence process and this has tremendous potential in the field of agricultural crop productivity. Therefore, it is very important to study mutant lacking GABA shunt enzymes to know the complete mechanism of nutrient remobilization in leaf senescence.

\section{Acknowledgement:}

This work was financially supported by Science and Engineering Research Board (SERB), Department of Science and Technology Govt. of India, New Delhi (Grant No.SB/SO/BB002/2012) to Mohammad Israil Ansari. 


\section{References:}

[1] Gan S \& Amasino RM, Plant Physiol. 1997 113: 313 [PMID: 12223609]

[2] Yap MN et al. Plant Mol Biol. 2003 51: 471 [PMID: 12650614]

[3] Guo Y \& Gan S, Curr Top Dev Biol. 2005 71: 83 [PMID: 16344103]

[4] Lim PO et al. Ann Rev Plant Biol. 2007 58: 115 [PMID: 17177638]

[5] Guo Y, Plant Mol Biol. 2013 82: 519 [PMID: 23065109]

[6] Sakamoto W \& Takami T, J Exp Bot. 2014 65: 3835 [PMID: 24634485]

[7] Nooden LD \& Guiamet JJ, Physiol Plant. 1989 77: 267

[8] Ansari MI et al. Physiol Plant. 2005 123: 1

[9] Humbeck K, Plant Mol Biol. 2013 82: 529 [PMID: 23315005]

[10] Guo Y \& Gan SS, J Exp Bot. 2014 65: 3901 [PMID: 24935620]

[11] Gregerson PL et al. Plant Mol Biol. 2013 82: 603 [PMID: 23354836]

[12] Guo Y \& Gan SS, Plant Cell Environ. 2012 35: 644 [PMID: 21988545]

[13] Jibran R et al. Plant Mol Biol. 2013 82: 547 [PMID: 23504405]

[14] Ansari MI \& Chen SCG, Int J Integrative Biol. 2009 6: 27

[15] Sun $X$ et al. J Integrative Plant Biol. 2013 55: 1038 [PMID: 23758915]
[16] Bouche N et al. Proc Natl Acad Sci USA. 2003 100: 6843 [PMID: 12740438]

[17] Varju P et al. Cell Tissue Res. 2001 30: 239

[18] Kinnersley AM \& Turano FJ, Crit Rev Plant Sci. 2000 19: 479

[19] Ludewig F et al. PLoS One. 2008 3: 3383 [PMID: 18846220]

[20] Bouche N \& Fromm H, Trends Plant Sci. 2004 9: 110 [PMID: 15003233]

[21] Van Cauwenberghe OR et al. Can J Bot. 2002 80: 933

[22] Breitkreuz KE et al. FEBS Lett. 1999 450: 280 [PMID: 10359089]

[23] Barbosa JM et al. Plant Physiol Biochem. 2010 48: 443 [PMID: 20303774]

[24] Akcay N et al. J Plant Physiol. 2012 169: 452 [PMID: 22189426]

[25] Buchnan-Wallaston V, J. Exp. Bot. 1997 48: 181

[26] Feller U \& Fischer A, Crit Rev Plant Sci. 1994 13: 241

[27] Miflin BJ \& Habash DZ, J Exp Bot. 2002 53: 979 [PMID: 11912240]

[28] Satya Narayan V \& Nair PM, Phytochem. 1990 29: 369

[29] Shelp BJ et al. Trends Plant Sci. 1999 4: 446 [PMID: 10529826]

[30] Katz E et al. J Exp Bot. 2011 62: 5367 [PMID: 21841177]
Edited by $P$ Kangueane

Citation: Ansari et al. Bioinformation 10(12): 734-736 (2014)

License statement: This is an open-access article, which permits unrestricted use, distribution, and reproduction in any medium, for non-commercial purposes, provided the original author and source are credited 